\title{
Towards in-cylinder Chemical Species Tomography on large-bore IC engines with pre-chamber
}

\author{
Tsekenis $S A^{a}$, Wilson $D^{b}$, Lengden $\mathrm{M}^{b}$, Hyvönen $\mathrm{J}^{\mathrm{d}}$, Leinonen $\mathrm{J}^{\mathrm{d}}$, Shah $\mathrm{A}^{\mathrm{c}}$, Andersson $\ddot{O}^{\mathrm{c}}$, McCann $\mathrm{H}^{\mathrm{a}}$ \\ ${ }^{a}$ School of Engineering, The University of Edinburgh, Edinburgh, EH9 3JL, United Kingdom \\ ${ }^{\mathrm{b}}$ Centre for Microsystems \& Photonics, University of Strathclyde, Glasgow, G1 1XW, United Kingdom \\ ${ }^{c}$ Division of Combustion Engines, Lund University, Lund, SE-221 00, Sweden \\ 'Wärtsilä Finland Oy, Vaasa, FI-65101, Finland
}

Corresponding author: Tsekenis SA, a.tsekenis@ed.ac.uk

\begin{abstract}
A feasibility study is presented and the achieved key design milestones towards the first application of Chemical Species Tomography by Near-IR Absorption Tomography on a heavy duty, large-bore marine engine to visualise relative mixture strength are described. The engine is equipped with pre-chamber ignition and operates using Liquefied Natural Gas with $>88.9 \%$ methane content. Operation of the engine under maximum-load conditions is a key design requirement, with peak cylinder pressure and mean temperature exceeding 127,510 Torr $(170 \mathrm{bar})$ and $850 \mathrm{~K}$ respectively. The near-IR spectroscopic behaviour of methane is examined for suitable absorption and reference regions for the above application. In particular, the spectroscopic absorption around the $2 v 3$ transition region near $1,666 \mathrm{~nm}$ is approximated by simulation using data from the HITRAN database under worst-case conditions. The simulation results are compared with methane spectra experimentally acquired at high temperature and ambient pressure. Interference from other chemical species as well as measurement linearity is also investigated. A 31-laser beam tomographic imaging array is proposed, which has been optimised to achieve higher spatial resolution performance in the vicinity of the pre-chamber's orifices. To enable optical access, a novel, minimally-intrusive method is presented, utilising standard fibreoptics and collimators.
\end{abstract}

Keywords Chemical Species Tomography, in-cylinder engine diagnostics, marine engine, prechamber, infra-red absorption spectroscopy

\section{Introduction}

Internal Combustion (IC) engines are currently in widespread application and will remain so for the foreseeable future. The combustion process of fossil fuels to drive these engines produces a multitude of reaction products, many of which are released into the atmosphere as gaseous and particulate emissions. Due to the detrimental effects of these emissions on the environment and health, they are stringently regulated with increasingly demanding allowable limits.

An important application of IC engines is heavy-duty marine propulsion and energy generation, with $90 \%$ of world trade carried by sea using 50 thousand merchant ships and 1 million seafarers (International Chamber of Shipping, 2013). Research is underway (Shah et al., 2014) to substitute the diesel fuel these engines commonly use with surrogate fuels for economic, practical and environmental reasons. Liquefied Natural Gas (LNG), composed primarily of methane, is an attractive option as its combustion inherently produces reduced $\mathrm{CO}_{2}$ emissions and particulate matter. However, there are difficulties presented in its wider adoption as a fuel due to its premature ignition at high compression ratios and high $\mathrm{NO}_{x}$ emissions. A condition is desirable where the mixture is rich enough (high enough fuel to air ratio) to be reliably ignited, yet lean enough to maintain low $\mathrm{NO}_{\mathrm{x}}$ emission levels. In achieving this balance, a fundamental understanding of the mixing process is key. That is to say that the fuel-air mixture stratification, or fuel concentration distribution, must be visualised.

The requirements for an ideal engine diagnostic system have been previously (Terzija et al., 2015) listed. Of particular interest to this application are the ability to visualise the fuel-air mixing process in a minimally-intrusive manner and the ability to do so at maximally-realistic so-called 'production' engine operating conditions. There is extensive research on laser diagnostic techniques developed and applied to combustion research (Aldén et al., 2011; Sick, 2013). From these, Planar Laser Induced Fluorescence (PLIF) and chemiluminescence are commonly used to study the mixing and ignition processes respectively. The excellent spatial and temporal resolution achievable by these techniques comes at the cost of considerable engineering complexity. For example, two-axis and/or through- 
piston optical access is required with significant modifications to the engine, detracting from the aforementioned requirements. In addition, any modifications to the engine to achieve optical access must be able to withstand the pressure rise and temperature of the combustion process, a factor which has limited optically-accessible engines from operating at their rated cylinder pressure.

The method of Chemical Species Tomography (CST) by near-infrared absorption for in-cylinder gaseous fuel imaging has previously been applied to a multi-cylinder (Wright et al., 2010) and a single cylinder (Terzija et al., 2015) engine in a form that is chemically selective specifically to long-chain hydrocarbon molecules. This opto-electronic method utilises fibre optics to launch thin pencil-beams into the volume of interest and subsequently to collect them. The optical windows can be made very small and need not be continuous around the circumference of the combustion chamber. In addition, no dopants are required for chemical selectivity. As a result, this method is minimally-intrusive and can be applied to 'production' operating conditions where a 'steel' engine would normally be considered.

The application of CST in a robust instrumentation system is underpinned by the spectroscopic behaviour of the target species. Therefore, an in-depth understanding of the behaviour at relevant pressures and temperatures must be established by simulation and experimentally. Inside the combustion chamber conditions of highly elevated pressure and temperature are created, reaching 127,510 Torr (170 bar) and $855 \mathrm{~K}$ (further details given in Section 1.1). The spectroscopic behaviour of LNG (viz. methane) at these harsh conditions has, to our knowledge, not been studied for the purpose of spectroscopic measurements. Published studies have covered the ranges 93.758-675.1 Torr (0.125 - 0.9 bar) (Frankenberg et al., 2008), 7.05 - 975.1 Torr (0.01 - 1.3 bar) (Lackner et al., 2003), and 600.0 - 750.1 Torr (0.8 - 1 bar) (Shemshad, 2013). One study achieved 22,502 Torr (30 bar) and $473 \mathrm{~K}$ (Kopecek et al., 2005).

We report here the study of methane spectroscopy, by simulation and experimentally, at pressures and temperatures relevant to internal combustion engines. Subsequently, based on the spectroscopy results, we present the initial steps towards the first application of Chemical Species Tomography to a large-bore marine engine in order to non-intrusively visualise the concentration distribution of LNG, first in the main chamber and subsequently in the pre-chamber.

\subsection{Engine platform}

The engine is the Wärtsilä model $6 \mathrm{~L} 20$, part of the 20-based marine engine series (fig 1 ). The turbocharged, 4-stroke engine was designed for operation with direct injection of diesel fuel and spark ignition. The bore of the cylinders is $200 \mathrm{~mm}$.

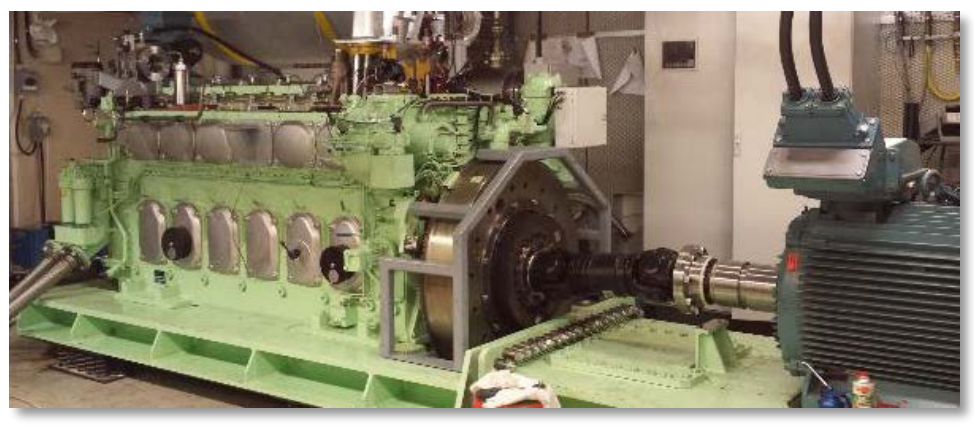

\begin{tabular}{|l|l|}
\hline \multicolumn{2}{|c|}{ Wärtsilä 6L20 } \\
\hline No. of cylinders & 6 \\
\hline Cylinder bore & $200 \mathrm{~mm}$ \\
\hline Stroke & $280 \mathrm{~mm}$ \\
\hline Displacement & $8.8 \mathrm{~L} / \mathrm{cyl}$ \\
\hline Max. speed & $1,000 \mathrm{RPM}$ \\
\hline Power output & $1,200 \mathrm{~kW}$ \\
\hline
\end{tabular}

Fig 1: Wärtsilä 6L20 engine on test bed at Lund University, Sweden.

The mean cylinder pressure $P$ was acquired using a pressure transducer during fired operation under normal load. The spatially averaged mean temperature $T$ of the gases inside the cylinder was calculated assuming an adiabatic compression process with an adiabatic index $\gamma=1.35$, initial pressure $P_{0}=3,000$ Torr (4 bar) and temperature $T_{0}=323 \mathrm{~K}$. The maximum pressure and temperature occur at 14.5 CAD (Crank Angle Degrees) after TDC (Top Dead Centre), i.e. TDC+14.5 CAD, when $P_{\max }=127,510$ Torr (170 bar) and $T_{\max }=855 \mathrm{~K}$ (fig 2). 


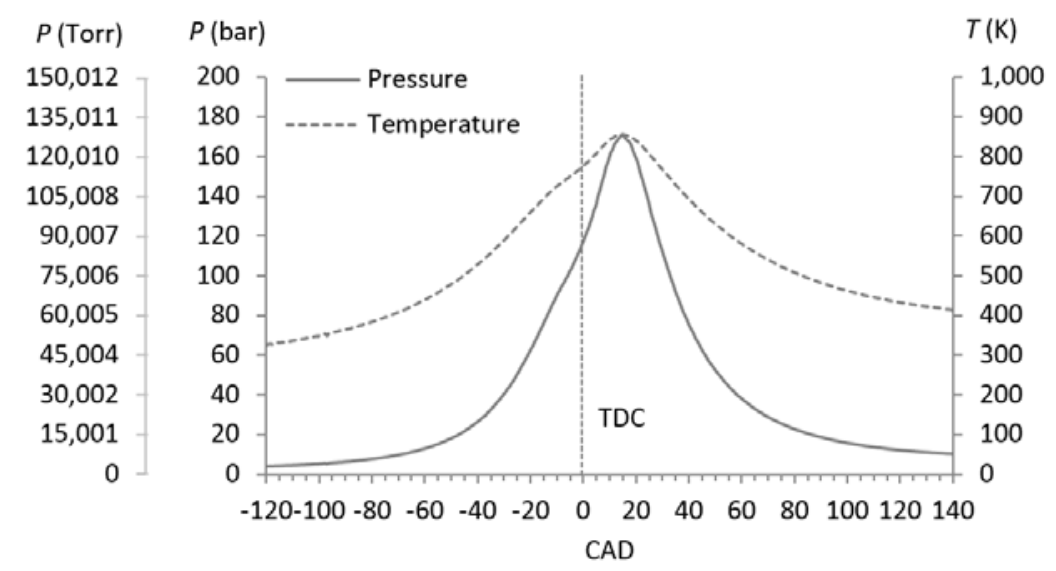

Fig 2: Pressure and temperature trace from the $6 \mathrm{~L} 20$ engine during fired operation as a function of CAD. The Top Dead Centre (TDC) marker is shown.

\subsection{Spectroscopy of methane in the Near Infra-Red region}

Methane is a spherical-top tetrahedral molecule with four $\mathrm{C}-\mathrm{H}$ bonds. The spectroscopic behaviour of methane has been studied extensively (Frankenberg et al., 2008; Shemshad et al., 2011) due to its importance in planetary and atmospheric processes, as well as in the mining industry.

Methane has fundamental vibrational modes $v_{1}-v_{4}$ near $3,312 \mathrm{~nm}$ (stretching asymmetric), 3,432 nm (stretching symmetric), 6,521 nm (bending asymmetric), and 7,627 nm (bending symmetric) (Shemshad, 2013). The resonant interaction between the vibrational energies gives rise to absorption lines in regions including near-IR. The near-IR region of the spectrum is of particular practical utility in spectroscopy instrumentation due to the availability of commercial coherent light sources and optical components (Carey et al., 2000).

In the near-IR region, the main overtone ro-vibrational combinations consist of the $v_{2}+2 v_{3}$ band around 1,300 nm (Gao et al., 2013) and the $2 v_{3}$ band around 1,666 nm (Gao et al., 2006). The $2 v_{3}$ band was selected for further study as it has been shown (Shemshad, 2013) that in the spectral region between $1,620 \mathrm{~nm}$ and $1,700 \mathrm{~nm}$ the interference from $\mathrm{H}_{2} \mathrm{O}, \mathrm{CO}$ and $\mathrm{CO}_{2}$ present in LNG is insignificant.

The spectral region between $1,620-1,700 \mathrm{~nm}$ (fig 3) contains the $6^{\text {th }}$ order energy level transition of the Q-branch $\left(\mathrm{Q}_{6}\right)$, P-branch $\left(\mathrm{P}_{6}\right)$ and R-branch $\left(\mathrm{R}_{6}\right)$ (Frankenberg et al., 2008).

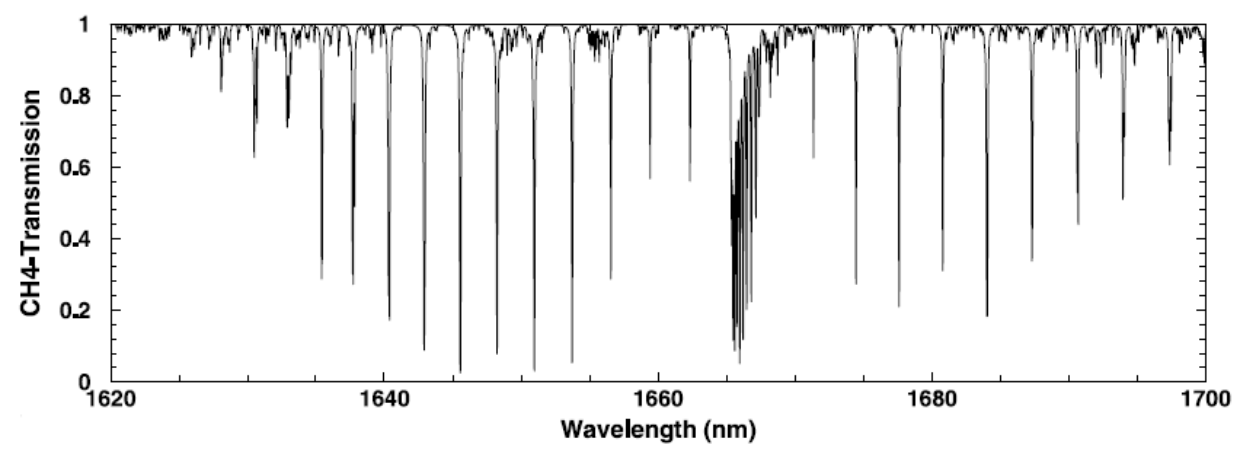

Fig 3: Spectrum of methane at room pressure and temperature between $1,620 \mathrm{~nm}$ and $1,700 \mathrm{~nm}$. Reproduced from (Shemshad, 2013). $P=760$ Torr ( $\approx 1$ bar), $T=294 \mathrm{~K}, L=10 \mathrm{~cm}$ and $n=10 \%$.

\section{Experimental}

LNG is composed of different molecular species, with methane having the highest volumetric concentration. For accurate spectroscopic measurements, the type and relative concentration of all constituents must first be quantified. Published compositions (Bakar and Semin, 2008; Srinivasan et al., 2004) of LNG indicate that the species content can vary significantly depending on the geographical origin and processing methods (table 1). 


\begin{tabular}{|c|c|c|}
\hline Molecule & \multicolumn{2}{|c|}{ \% relative volumetric concentration } \\
\hline Methane & 98.33 & $91.82-94.00$ \\
\hline Ethane & 0.11 & $2.91-3.30$ \\
\hline $\mathrm{CO}_{2}$ & 0.21 & $0.30-0.81$ \\
\hline $\mathrm{CO}$ & 0.01 & $<0.01$ \\
\hline $\mathrm{N}_{2}$ & 1.28 & $0.96-4.46$ \\
\hline $\mathrm{O}_{2}$ & 0.05 & 0.01 \\
\hline Hexane & 0.01 & $0.01-0.17$ \\
\hline Propane & 0.02 & $0.57-1.00$ \\
\hline i/n-butane, i/n-pentane & 0.01 & $<0.29$ \\
\hline Reference & (Srinivasan et al., 2004) & (Bakar and Semin, 2008) \\
\hline
\end{tabular}

Table 1: Published compositions of Natural Gas.

The exact composition of the transported gas is monitored by suppliers as it is related to the calorific content of the gas. The experimental facility in this study is operated by Swedegas and supplied with LNG from Dragor, using a single connection point in Denmark. The annual gas composition measurements were averaged over the period 2010 - 2014 (table 2).

\begin{tabular}{|c|cccccccccc|}
\hline Year & $\mathbf{C H}_{\mathbf{4}}$ & $\mathbf{C}_{\mathbf{2}} \mathbf{H}_{\mathbf{6}}$ & $\mathbf{C}_{\mathbf{3}} \mathbf{H}_{\mathbf{8}}$ & $\mathbf{i C}_{\mathbf{4}} \mathbf{H}_{\mathbf{1 0}}$ & $\mathbf{n C}_{\mathbf{4}} \mathbf{H}_{\mathbf{1 0}}$ & $\mathbf{i C}_{\mathbf{5}} \mathbf{H}_{\mathbf{1 2}}$ & $\mathbf{n C}_{5} \mathbf{H}_{\mathbf{1 2}}$ & $\mathbf{C}_{\mathbf{6}}+$ & $\mathbf{C O}_{\mathbf{2}}$ & $\mathbf{N}_{\mathbf{2}}$ \\
\hline 2014 & 89.28 & 5.89 & 2.37 & 0.37 & 0.56 & 0.13 & 0.08 & 0.05 & 0.92 & 0.34 \\
2013 & 89.90 & 5.63 & 2.02 & 0.33 & 0.46 & 0.13 & 0.07 & 0.05 & 0.91 & 0.51 \\
2012 & 88.90 & 6.10 & 2.44 & 0.37 & 0.54 & 0.13 & 0.08 & 0.06 & 1.04 & 0.35 \\
2011 & 89.13 & 5.98 & 2.35 & 0.37 & 0.54 & 0.13 & 0.08 & 0.06 & 0.97 & 0.36 \\
2010 & 90.01 & 5.69 & 2.17 & 0.37 & 0.53 & 0.13 & 0.08 & 0.06 & 0.65 & 0.31 \\
\hline \% Average & 89.44 & 5.86 & 2.27 & 0.36 & 0.53 & 0.13 & 0.08 & 0.06 & 0.90 & 0.37 \\
\hline
\end{tabular}

Table 2: Annual and averaged compositions of Natural Gas feeding the experimental facility.

It can be seen that methane is present at a mean relative volumetric concentration of $89.44 \%$, with ethane and propane then contributing $8.13 \%$ of the total volume. These concentrations were used in this study.

\subsection{Theoretical spectroscopic model}

The transmission of light though an absorbing material is described by the Beer-Lambert law (Platt and Stutz, 2008a)

$$
\operatorname{Tr}=\frac{I_{r}}{I_{S}}=e^{-\int_{0}^{L} k(P, T, \bar{v}) n d L}
$$

where $\operatorname{Tr}$ is the transmittance, $I_{\mathrm{r}}$ is the received intensity, $I_{\mathrm{S}}$ the intensity entering the material, $n$ is the molecular concentration of the material and $L$ is the path-length through the material. Ignoring scattering, $k$ is the absorption coefficient which is a function of pressure $P$, temperature $T$, and the frequency of the light $\bar{v}$. In turn, the absorption coefficient is given by (eqn. 2)

$$
k(P, T, \bar{v})=S^{\prime}(T) \varphi(\bar{v}, P, T) P
$$

where $S^{\prime}$ is the line-strength of the transition and $\varphi$ is the transition line-shape. The transition lineshape is determined by the collisions between the molecules (hereupon pressure broadening $\Delta \bar{v}_{\mathrm{C}}$ ), Doppler shift (hereupon Doppler broadening $\Delta \bar{v}_{\mathrm{D}}$ ) and the Heisenberg uncertainty principle $\Delta \bar{v}_{\mathrm{H}}$ (Banwell and Mccash, 1994; Platt and Stutz, 2008b). These effects are quantified as (eqn 3 - 5)

$$
\Delta \bar{v}_{\mathrm{C}}=P \sum_{i} n_{i} \Gamma_{i}\left(\frac{T_{o}}{T}\right)^{m_{i}}
$$

where $\Gamma_{\mathrm{i}}$ is the broadening coefficient for species with index $i$ at reference temperature $T_{\mathrm{o}}$ and $m_{\mathrm{i}}$ is the temperature exponent.

$$
\Delta \bar{v}_{\mathrm{D}}=\bar{v}_{o} \sqrt{\frac{8 k_{\mathrm{B}} T \ln (2)}{M c^{2}}}
$$


where $\bar{v}_{o}$ is the transition line centre, $k_{\mathrm{B}}$ is Boltzmann's constant, $M$ is the molar mass and $c$ is the speed of light.

$$
\Delta \bar{v}_{\mathrm{H}} \approx \frac{1}{2 \pi t}
$$

where $t$ is the lifetime of the exited electronic state.

Broadening due to the Heisenberg uncertainty principle for typically $t \approx 10^{-8} \mathrm{~s}$ results in a broadening of $\approx 10^{8} \mathrm{~Hz}$. Compared with the corresponding frequency of the wavelengths of interest $\left(\approx 10^{14} \mathrm{~Hz}\right)$, it can be seen that this factor is insignificant and we did not consider it further. Consequently, the transition line-shape will be dominated by Doppler broadening at low pressures and collisional broadening at high pressures.

The line-shape due to pressure broadening is approximated by a Lorentzian profile, whereas for the Doppler broadening by a Gaussian profile. The Voigt line-shape is simply the convolution of the two profiles and is given by (Lengden et al., 2013)

$$
\varphi(\bar{v}, P, T)=\frac{2 \sqrt{\ln (2)}}{\Delta \bar{v}_{D} \sqrt{\pi}} \frac{Y}{\pi} \int_{-\infty}^{\infty} \frac{e^{-z^{2}}}{Y^{2}+(X-z)^{2}}
$$

which can be approximated by (McLean et al., 1994)

$$
\varphi(\bar{v}, P, T) \approx \frac{2 \sqrt{\ln (2)}}{\Delta \bar{v}_{D} \sqrt{\pi}} \sum_{j=1}^{j=4} \frac{C_{j}\left(Y-A_{j}\right)+D_{j}\left(X-B_{j}\right)}{\left(Y-A_{j}\right)^{2}+\left(X-B_{j}\right)}
$$

where $A_{\mathrm{j}}$ to $D_{\mathrm{j}}$ are constants (table 3 ) and $X$ and $Y$ are determined by (eqn 8 )

$$
X=\frac{2 \sqrt{\ln (2)}}{\Delta \bar{v}_{D}}\left(\bar{v}-\bar{v}_{o}\right), Y=\frac{\Delta \bar{v}_{C} \sqrt{\ln (2)}}{\Delta \bar{v}_{D}}
$$

\begin{tabular}{|c|c|c|c|c|}
\hline $\mathbf{j}$ & $\boldsymbol{A}_{\mathbf{j}}$ & $\boldsymbol{B}_{\mathbf{j}}$ & $\boldsymbol{C}_{\mathbf{j}}$ & $\boldsymbol{D}_{\mathbf{j}}$ \\
\hline 1 & -1.2510 & 1.2359 & -0.3085 & 0.0210 \\
\hline 2 & -1.3509 & 0.3786 & 0.5906 & -1.1858 \\
\hline 3 & -1.2510 & -1.2359 & -0.3085 & -0.0210 \\
\hline 4 & -1.3509 & -0.3786 & 0.5906 & 1.1858 \\
\hline
\end{tabular}

Table 3: Constants for the line-shape approximation (McLean et al., 1994).

Using the required data from the HITRAN database (Rothman et al., 2013) and assuming the pressure broadening to be purely due to methane-methane and methane-air collisions, the experimental spectrum of fig 3 was reproduced in fig 4 to validate the model, showing good agreement.

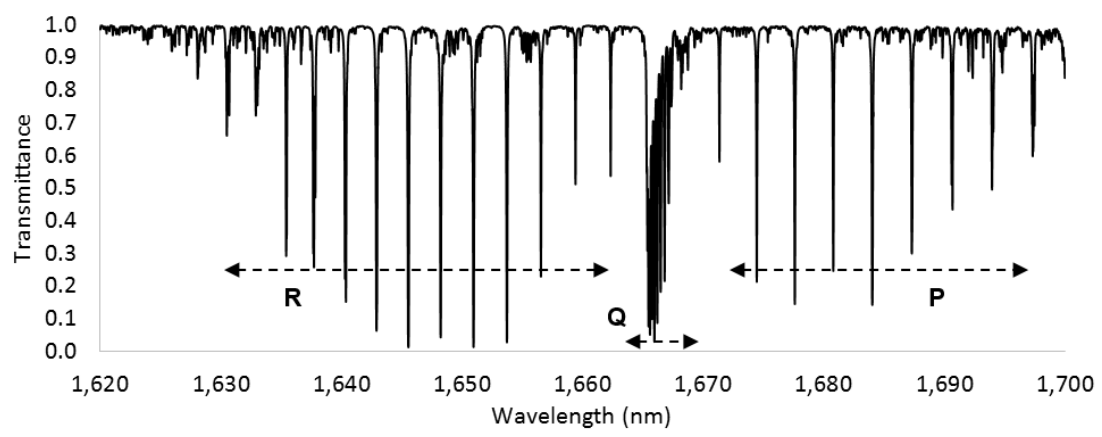

Fig 4: Simulated spectrum of methane at identical conditions to spectrum of fig 3 , using model described in Section 2.1. The $\mathrm{P}_{6}, \mathrm{Q}_{6}$ and $\mathrm{R}_{6}$ branches are shown. $P=750$ Torr $(\approx 1$ bar), $T=294 \mathrm{~K}$, $L=10 \mathrm{~cm}$ and $n=10 \%$.

\subsection{Simulation results \& discussion}

Using the validated model (Section 2.1) to generate simulated spectra, the absorption of methane was studied in the spectral region of $1,620-1,700 \mathrm{~nm}$. The effect of pressure was initially investigated (fig 5), increasing the pressure in increments of 3,750 Torr up to 22,502 Torr (5 bar up to 30 bar) followed by increments of 7,501 Torr up to 150,012 Torr (10 bar up to 200 bar). The temperature was 
kept constant at $294 \mathrm{~K}$, the path-length set to $10 \mathrm{~cm}$ and the volumetric concentration of methane to $10 \%$ (the balance being a non-absorbing medium). All spectra in fig $5-7,9$ and 11 are simulated.

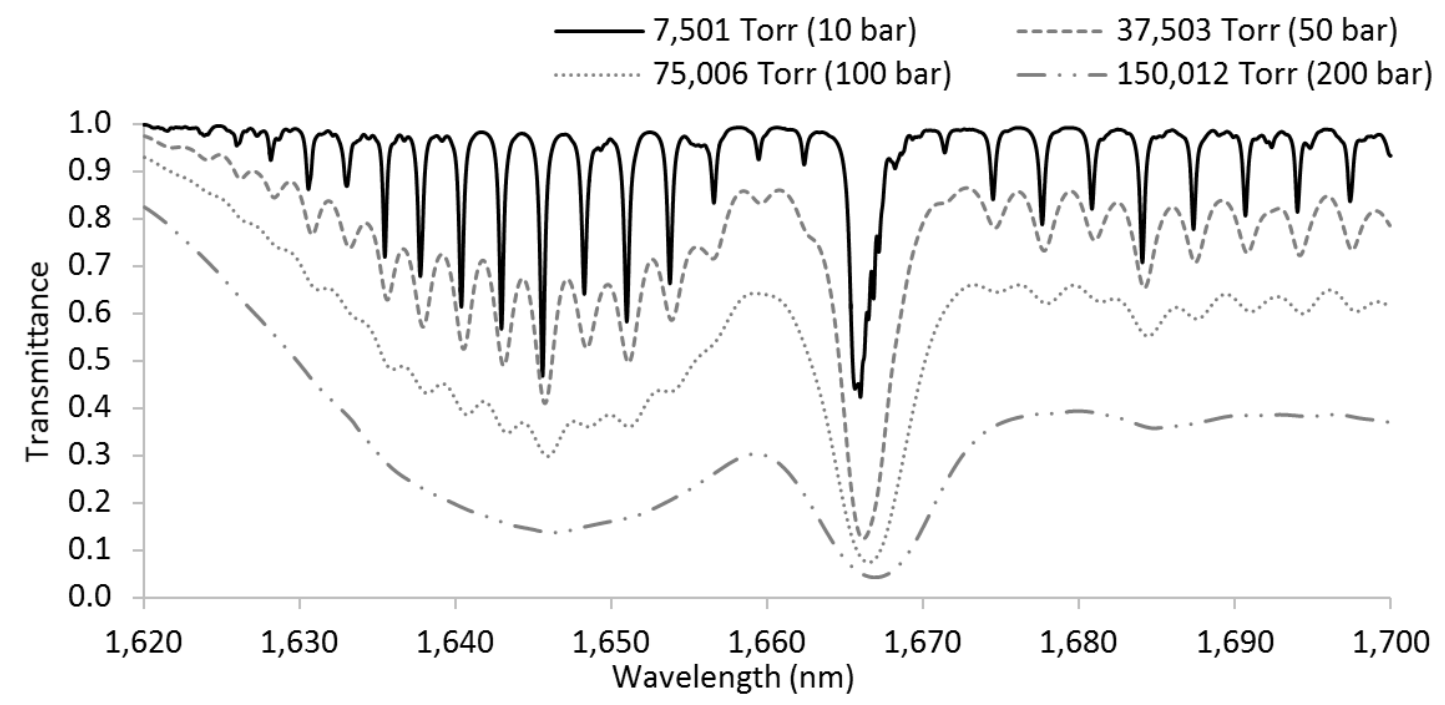

Fig 5: Selected methane spectra from pressure sweep. For all plots, $T=294 \mathrm{~K}, L=10 \mathrm{~cm}$ and $n=10 \%$.

It can be seen from fig 5 that the pressure broadening at high pressures is dramatic, in line with expectations. The fine features in the $\mathrm{P}$ and $\mathrm{R}$ branches become indistinguishable. Moreover the $\mathrm{Q}$ branch is severely broadened with a FWHM of $10 \mathrm{~nm}$ and the peak of the compound absorption feature spectrally shifted by more than $1 \mathrm{~nm}$. Finally, comparing the spectra at 37,503, 75,006 and 150,012 Torr (50, 100 and 200 bar), saturation of the absorption feature is evident i.e. the absorption is highly non-linear as a function of molecular concentration. These observations suggest that extracting concentration data under these conditions would have been challenging.

Subsequently, the effect of temperature was investigated with a temperature sweep from $300 \mathrm{~K}$ to $1,300 \mathrm{~K}$ in $100 \mathrm{~K}$ increments (fig 6). The pressure was kept constant at 150,012 Torr (200 bar), the path-length set to $10 \mathrm{~cm}$ and the volumetric concentration of methane to $10 \%$.

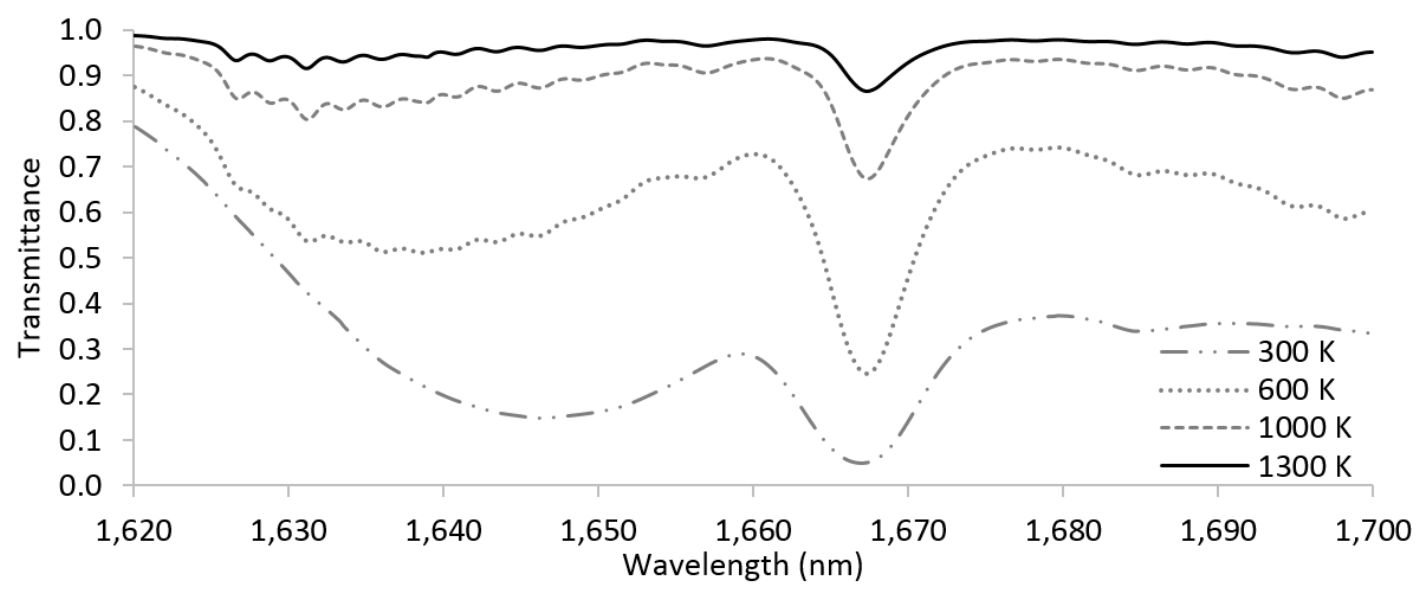

Fig 6: Selected methane spectra from temperature sweep. For all plots, $P=150,012$ Torr (200 bar), $L=10 \mathrm{~cm}$ and $n=10 \%$.

Examining the effect of temperature in fig 6, it can be seen that temperature, via weakening of the linestrength, 'counteracts' the broadening effect of elevated pressure. The Voigt line-shapes arising at elevated temperature are not, however, identical to the line-shapes at lower pressure. That is to say, raising the temperature is not equivalent to lowering the pressure.

The effects of temperature and pressure were investigated in tandem, for the expected engine conditions as shown in the pressure trace of fig 2 and spectra were plotted (fig 7). 

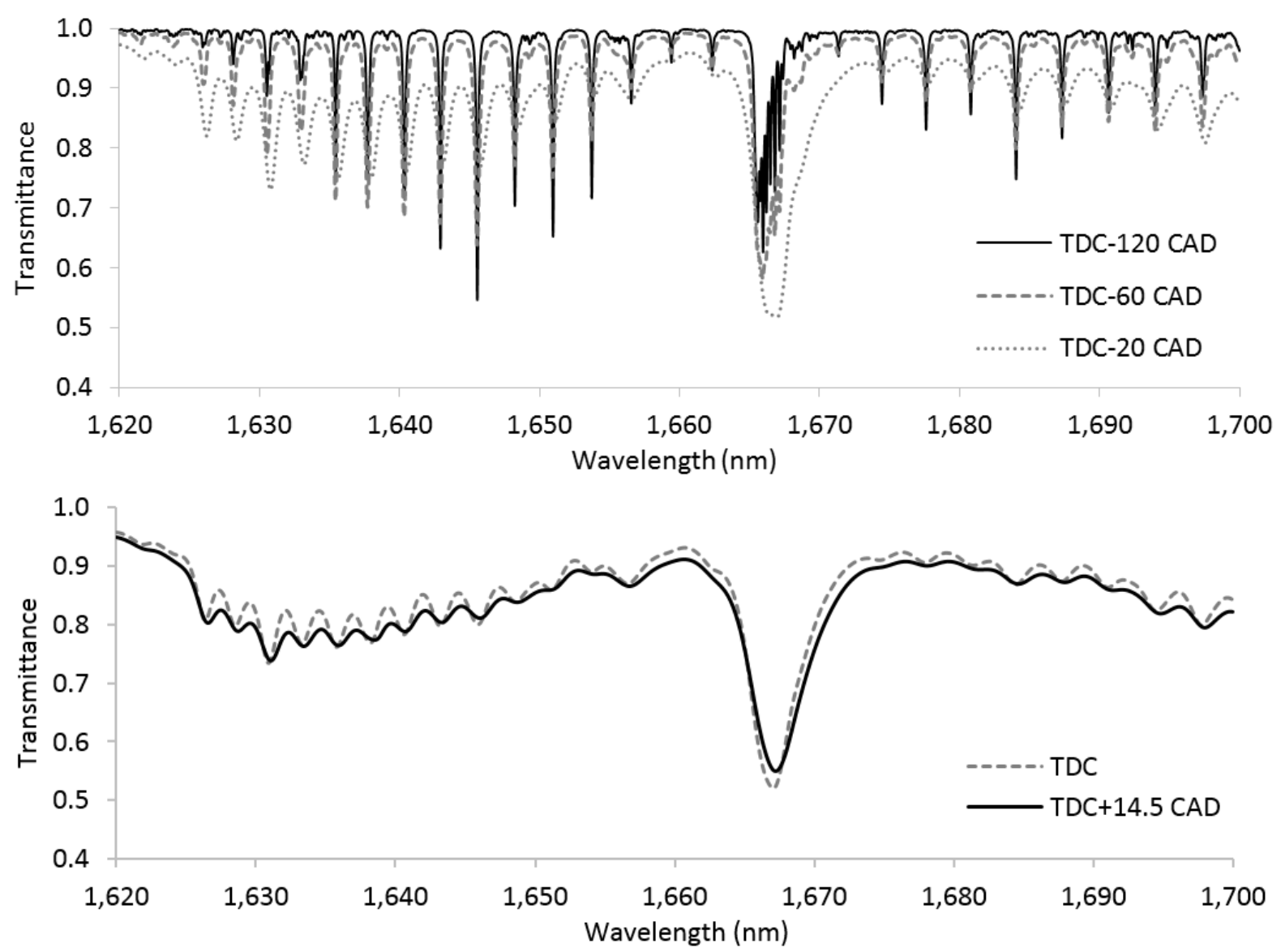

Fig 7: Methane spectra at selected temporal positions (CAD) within an engine cycle at the corresponding temperature and pressure conditions seen in fig 2 . For all plots, $L=10 \mathrm{~cm}, n=10 \%$.

The simulated spectra of fig 7 at realistic conditions found in the engine to be instrumented demonstrate the benefit of treating pressure and temperature in tandem. Contrary to the previous investigation where the effects were treated in isolation, it can now be seen that by carefully targeting a suitable absorption line, spectroscopic access is viable.

\subsection{Experimental results \& discussion}

The spectroscopic parameters in the HITRAN database have been acquired at a broad variety of conditions and using various methods. Therefore, the simulated spectra should be treated as a first approximation and verified experimentally at the desired pressure and temperature.

The spectroscopic behaviour of methane was investigated using a spectrometer capable of reaching the temperature present in the engine's combustion chamber. The maximum pressure attainable was limited to 750 Torr (1 bar) due to the cell design.

The experimental setup, described previously (McGettrick et al., 2009) in more detail, uses a DFB diode laser $(\mathrm{OKI})$ tunable over $1,645.45-1,651.40 \mathrm{~nm}$. The laser's initial wavelength is set via temperature tuning and then a $100 \mathrm{~Hz}$ saw-tooth current ramp is applied to wavelength-modulate the laser over the spectral feature of interest. The fibre-coupled output from the laser is connected to a $50: 50$ optical fibre splitter, with one output connected to a fibre ring-resonator used for wavelength referencing and the other output connected to a collimator. Light from the collimator passes through an inner glass cell that is $5.5 \mathrm{~cm}$ in length and made out of fused-silica. This inner cell is enclosed within a larger fused-silica outer cell and the whole glass arrangement is located within a furnace that can achieve controlled temperatures in excess of $1,200 \mathrm{~K}$. The outer cell is continually supplied with dry nitrogen. The inner cell is evacuated with a vacuum pump and then supplied with $100 \%$ research grade methane via a mass-flow controller until atmospheric pressure is attained. The gas then remains static within the cell for five minutes prior to measurement to ensure its temperature has stabilised. The light transmitted through the glass cell is collected using a photodiode receiver. At the beginning of each experiment the inner cell is purged with $100 \%$ dry nitrogen to provide a base-line reference signal in the absence of methane. 
Three sets of experiments were performed using pure methane and covering the spectral regions associated with the $R_{4}, R_{5}$ and $R_{6}$ manifolds. For each spectral region, the transmittance profile at $773 \mathrm{~K}, 873 \mathrm{~K}$ and $973 \mathrm{~K}$ was acquired and plotted (fig 8). The simulated transmittance profile at $873 \mathrm{~K}$, generated using the model described in Section 2.1, has been added for comparison.
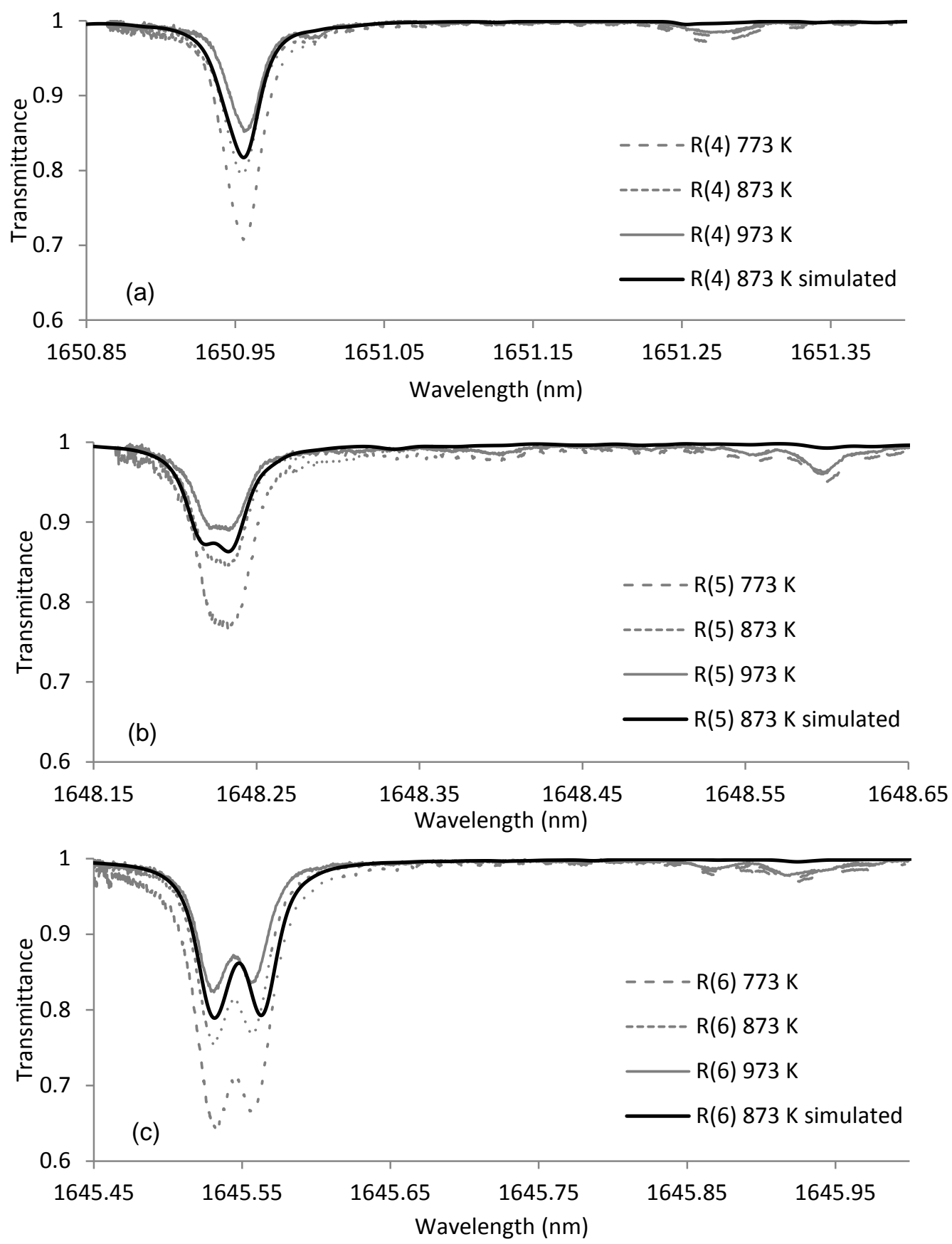

Fig 8: Experimentally acquired transmission spectra of pure methane for the spectral regions associated with the $R_{4}, R_{5}$ and $R_{6}$ manifolds ( $a, b, c$, respectively). Modelled spectra at $873 \mathrm{~K}$ shown for comparison. For all plots, $P=750$ Torr (1 bar), $L=5.5 \mathrm{~cm}, n=100 \%$.

Examining the transmittance profiles (fig 8), transmittance increases as temperature increases due to weakening of the line-strength. The position shift of transmittance features as a function of temperature is negligible in all manifolds. The $R_{5}$ profile shows a wider feature, while the $R_{6}$ profile contains two distinct transmittance troughs. The profile generated by simulation correlates well with the experimental results in the cases of $R_{4}$ and $R_{5}$, both in terms of amplitude and position. In the case of $R_{6}$, there is significant shift between the simulated and experimental profiles, despite the simulated profile also successfully showing two distinct troughs. 
Examining the spectral regions surrounding the transmittance troughs, features are evident near $1,651.00 \mathrm{~nm}$ and 1,651.30 nm (fig 8a), 1,648.35 - 1,648.60 nm (fig 8b) and 1,645.85 - 1,646.00 nm (fig 8c). These features, identified experimentally, do not appear in the simulated profiles. There is limited information available in the HITRAN database to fully model these features commonly referred to as 'hot lines'. Indeed, previous experimental investigations of the $\mathrm{R}_{4}$ manifold (McGettrick et al., 2009), centred around $1,650.8 \mathrm{~nm}$, identified a number of spectral features at temperatures greater than $773 \mathrm{~K}$ that are not present in the HITRAN 2012 database.

These unidentified features due to 'hot lines' are isolated from the main manifolds at low pressures. However, at the pressures generated during the compression stroke, these features will become broader and contribute to the background transmittance continuum. If unaccounted for, features due to 'hot lines' can introduce significant errors in the measured methane concentration. Therefore, further work using a high pressure cell is needed to fully characterise the features around the main manifolds, ensuring accurate concentration measurements are obtained during engine operation.

\section{Tomography system development}

The tomography data acquisition system considered for this application has been previously described in detail (Wright et al., 2010), albeit for different wavelengths. The system can sample up to 32 sampling beams at $100 \mathrm{kS} / \mathrm{s}$. Here we present the design of the modifications required to utilise the instrumentation system in this application.

\subsection{Selection of spectroscopic lines}

Selection of the spectral region and transition(s) is a compromise between the spectroscopic behaviour of the target species, interference from other species and availability of light sources.

For methane, the $\mathrm{Q}$ branch near $1,667 \mathrm{~nm}$ appears attractive, as it demonstrates the strongest absorption (fig 4). However, the $\mathrm{Q}_{6}$ branch comprises numerous closely neighbouring lines of significant strength. Consequently, the structure of the resulting feature is complex at room conditions and becomes unstructured early in the compression stroke of the engine cycle as the pressure rises. This is accompanied by a significant shift of the apparent absorption peak. For these reasons this spectral region is a poor choice.

On the other hand, the $\mathrm{R}$ branch offers a selection of easily distinguishable and strong absorption lines. From these, the $R_{4}$ manifold near $1,651 \mathrm{~nm}$ and $\mathrm{R}_{6}$ manifold near $1,645 \mathrm{~nm}$ promise the best SNR, $R_{6}$ having the strongest absorption. Both regions have been used successfully in the past (Cubillas et al., 2007; Well et al., 2005) for methane detection and diode-based lasers are readily available for both. The highest SNR results from the $R_{6}$ transition with symmetry species $A_{1}$ at $1,645.53 \mathrm{~nm}$ with a line-strength of $3.05 \cdot 10^{-2} \mathrm{~cm}^{-2} \mathrm{~atm}^{-1}$ (Rothman et al., 2013). The modelled spectral shift of the feature's peak remains $<0.3 \mathrm{~nm}$ over the entire range of engine operating conditions. The final choice between the $\mathrm{R}_{4}$ or $\mathrm{R}_{6}$ manifolds should however take into consideration the behaviour of 'hot line' features at elevated pressures, as discussed in Section 2.3.

With regards to interference from other molecules, these must be investigated individually. Ethane, appearing in the highest volumetric concentration after methane, as well as the heavier hydrocarbons and nitrogen have been investigated as part of Natural Gas spectroscopy studies (Burns and Ciurczak, 2007; Dantas et al., 2014). It was shown that the spectra of heavier hydrocarbons are weaker and broader than methane and that, in general, $97 \%$ of the absorption variance between varying mixtures of Natural Gas components is solely due to methane.

$\mathrm{CO}_{2}$ has documented absorption lines in the region 1,500-1,700 nm. Spectra for $\mathrm{CO}_{2}$ were created by simulation (fig 9 ) at best (least broadening) and worst-case (most broadening) engine conditions. All other parameters were identical to the methane spectra. 


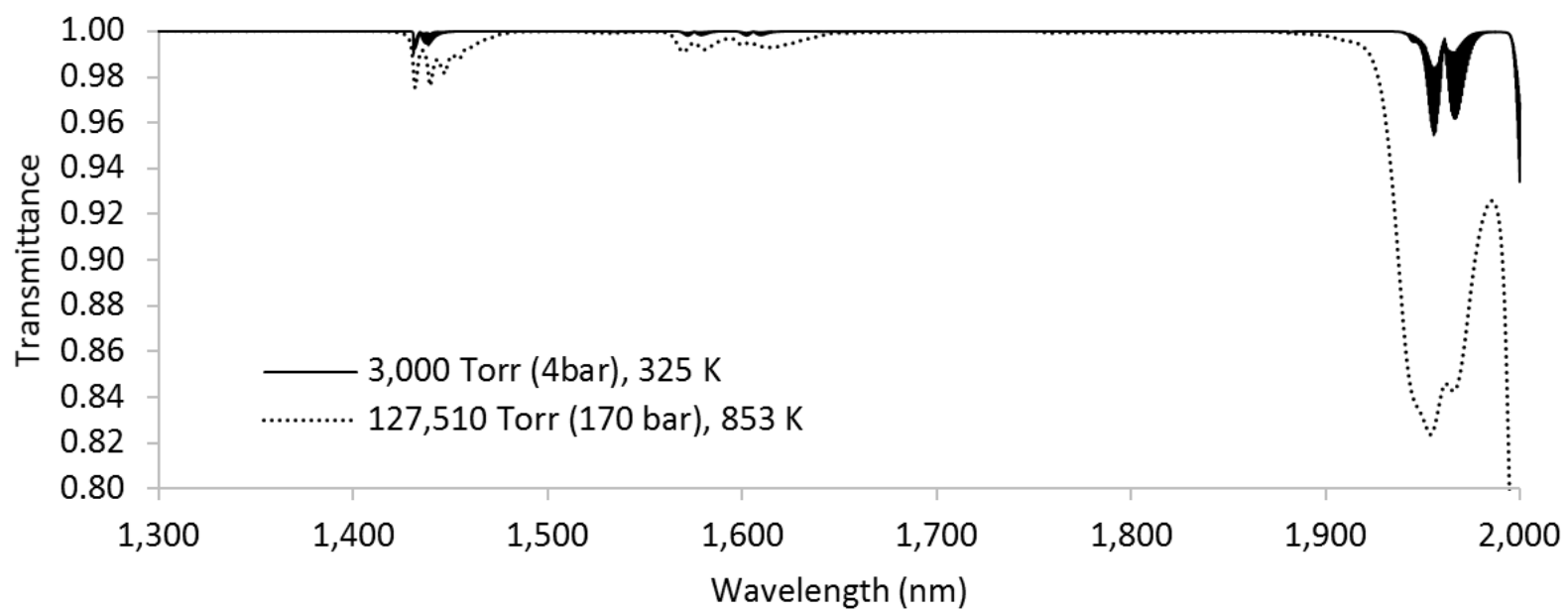

Fig 9: $\mathrm{CO}_{2}$ spectra at the two extremes of in-cylinder conditions. $L=10 \mathrm{~cm}, n=10 \%$.

It can be seen that, in the region of interest between 1,500 - 1,700 nm, absorption remains below $3 \%$ under all engine conditions. When compounded with the maximum volumetric concentration in the Natural Gas supply of $0.9 \%$, the contribution of $\mathrm{CO}_{2}$ is insignificant.

\subsection{Linearity at high concentrations}

The significant spectroscopic absorption of methane near 1,645 nm at 170 bar and $854 \mathrm{~K}$ motivates an investigation to quantify the linearity of absorption versus the product of concentration and path-length. A linear absorption model is favourable for tomographic image reconstruction.

For the $6 \mathrm{~L} 20$ engine, the expected air-fuel equivalence ratio $(\lambda)$ ranges between $1.80-2.33$ for the main combustion chamber and $0.76-1.10$ for the pre-combustion chamber. Adding a margin in the value of $\lambda$ of $\pm 20 \%$, the corresponding air-fuel volumetric ratio (AFR) was calculated (fig 10). The calculation was based on the oxidation reaction of methane, the stoichiometric AFR being equal to 17.2. Transmittance was plotted (fig 10) against $\lambda$ under worst-case conditions for a path-length of $20 \mathrm{~cm}$ to represent the cylinder bore and $4 \mathrm{~cm}$ to represent the pre-chamber. The $R^{2}$ values resulting from least-squares fitting to a linear function suggest that a linear molecular concentration vs absorption model can be adopted with insignificant loss of accuracy.
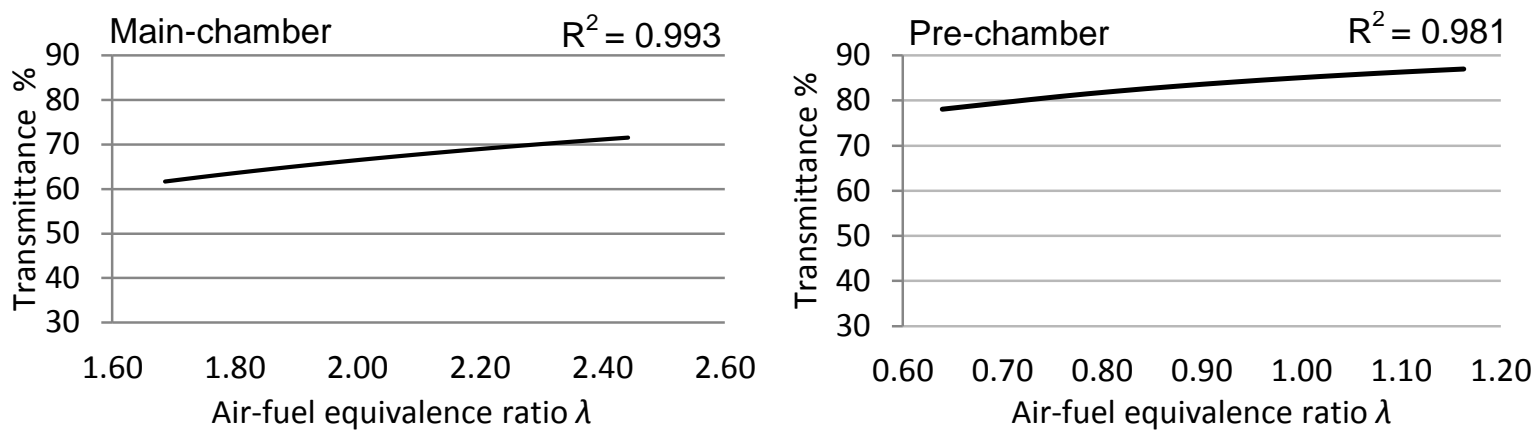

Fig 10: Transmittance versus expected air-fuel equivalence ratios for the main-chamber (left) and the pre-chamber (right).

\subsection{Spectroscopic access schemes}

A number of techniques are available for accessing the absorption feature near $1,645 \mathrm{~nm}$ and ultimately quantifying the species molecular concentration. Direct Absorption (DA) spectroscopy, Tunable-Diode Laser Absorption Spectroscopy (TDLAS) with or without Wavelength Modulation (WMS), with or without harmonic compensation ( $2 f / 1 f$ ) can all be used. There is extensive literature on all techniques and their variations.

From these techniques DA is computationally and experimentally the simplest, albeit the most susceptible to 'noise' arising from the environment of the instrument, primarily signal extinction mechanisms such as beam-steering and scattering from oil particles. In past engine applications (Terzija et al., 2015; Wright et al., 2010) a second non-absorbed reference beam has been 
successfully employed, traversing the same path as the absorbed beam, to suppress non speciesspecific effects and termed the Dual-Wavelength Ratiometric (DWR) method.

TDLAS with WMS has achieved detection of spectrally narrow and weak absorption features in a number of applications. However, detection requires lock-in detectors which can be prohibitively expensive in a multi-channel tomography application. Most importantly, the technique requires increasingly deeper modulation of the laser source to fully scan pressure-broadened features, introducing modulation non-linearity (Li et al., 2006) at elevated pressures.

The application in this paper covers a wide range of pressure and concentration. We therefore propose a hybrid scheme utilising WMS at low pressures and DA with DWR at high pressures. The instrumentation system can rapidly switch from WMS to DA by ceasing wavelength modulation of the absorbed wavelength. However, this will require extraction of the DC component of the received signal.

The reference wavelength for the DWR technique must be chosen to be as spectrally near as possible to the measurement wavelength to minimise dispersion effects. For this purpose the region near $1,550 \mathrm{~nm}$ contains very weak absorption lines for methane resulting in virtually zero absorption (fig 11). This region is free from interference from other species found in combustion engines as shown by (Carey et al., 2000). Finally, DFB lasers are mass-produced for telecommunications and are readily available.

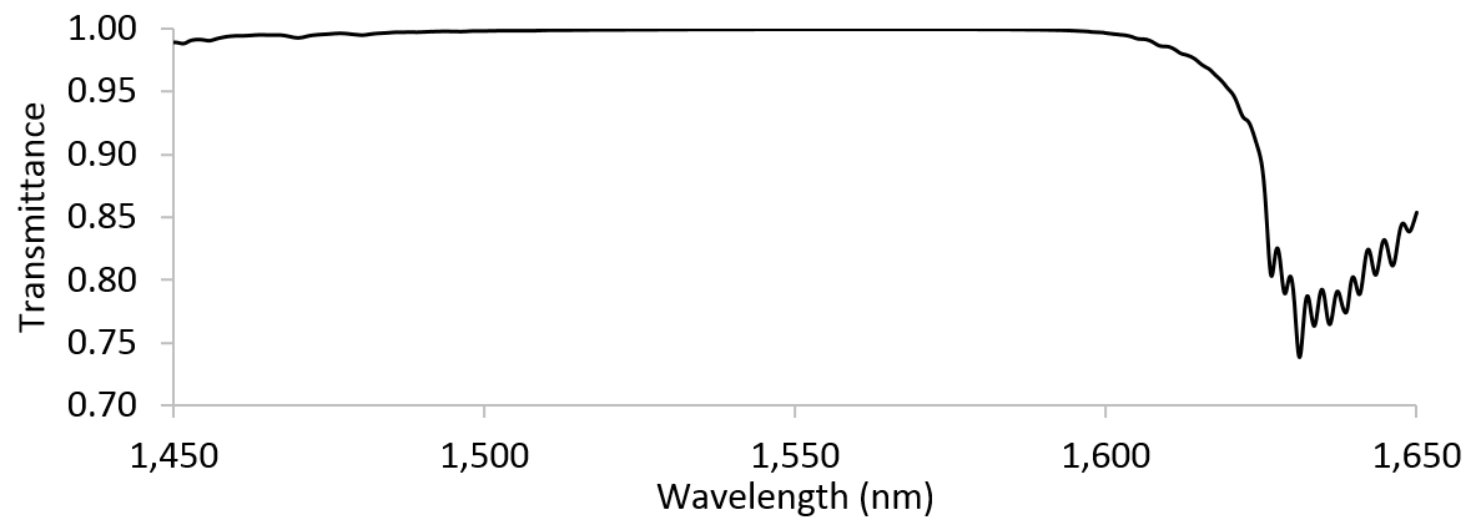

Fig 11: Methane transmittance near 1,550 nm. $P=127,510$ Torr (170 bar), $T=853 \mathrm{~K}, L=10 \mathrm{~cm}$, $n=10 \%$.

\subsection{Engine Optical Access}

Due to the high pressure developed during the compression stroke up to 150,012 Torr (200 bar), diagnostic methods requiring the conventional Bowditch type piston extension and optical access windows cannot be used. Instead, as the tomographic system utilises fibre-optics, we propose a novel method exploiting the cylinder liner which, in a marine engine, can be sufficiently large to accommodate embedded optical elements. A section-view of the engine liner is shown in fig 12 , along with our proposed optical access method.
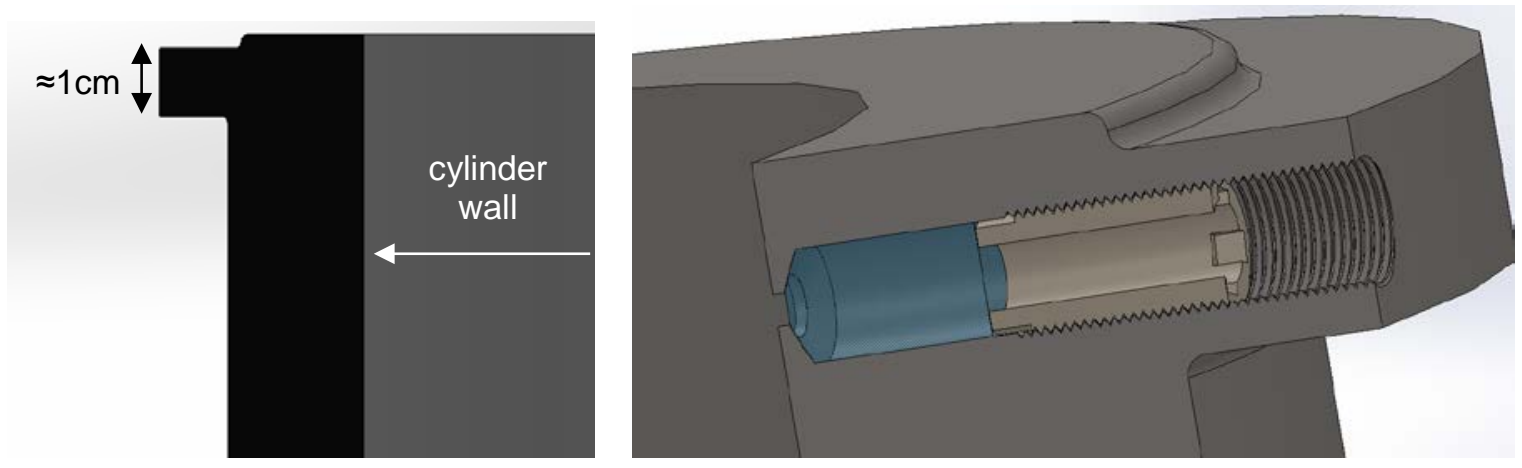

Fig 12: Section view of Wärtsilä 6L20 cylinder liner (left) and proposed optical access method (right). 
The optical access method comprises of an aperture in the combustion chamber plugged by sapphire which has been ground to a cylinder with both ends polished. The sapphire plug is held in place by a keyed and hollow set-screw. The surface area exposed to the combustion chamber is limited by the force applied on the face of the sapphire plug due to the pressurised chamber. At maximum cylinder pressure and an aperture diameter of $2 \mathrm{~mm}$, the force exerted on the sapphire plug is equivalent to $\approx 64 \mathrm{~N}$. This aperture allows the beam from a fibre-pigtailed GRIN collimator to be launched into the combustion chamber while the sapphire plug shields the collimator and fibre from the combustion process. Due to the fibre and collimation optics not being an integral part of the optical access method, they can be substituted to accommodate other wavelengths to target additional species.

\subsection{Tomography arrays}

Two beam arrays have been designed, using 26 and 31 beams in a co-planar grid configuration. The 26-beam array (fig 13) will image the concentration distribution of methane inside the main combustion chamber. It consists of 6 projections of 9-2-2-9-2-2 beams respectively, arranged in a quasi-regular pattern with the objective being to maximise the number of projections and inter-beam spacing, and spanning the sinogram space (Terzija et al., 2008) as widely as possible. No additional beams could be utilised due to the length of the optical access ports in the liner. Because of the relatively small number of beams available to cover the entire bore cross-section area, optimisation of beam placement was deemed superfluous.
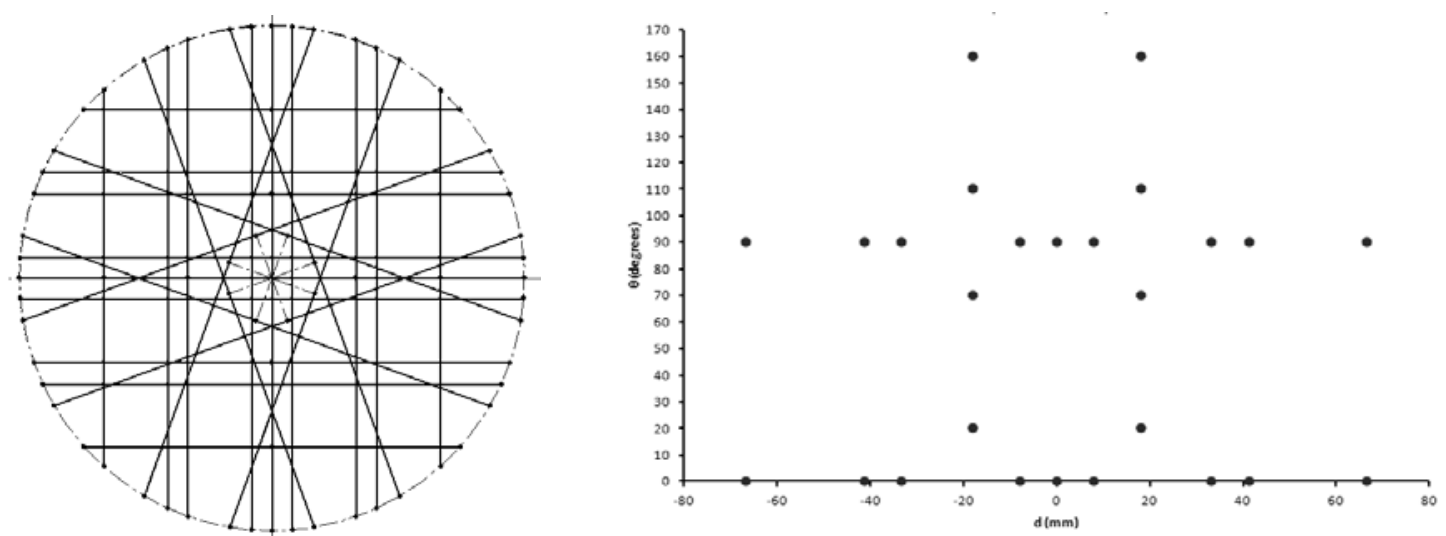

Fig 13: 26-beam tomography array (left) and sinogram representation (right) to image the overall main combustion chamber.

The 31-beam array (fig 14) aims to offer insight into the concentration distribution immediately at the 6 exit orifices of the pre-chamber. The beams are concentrated immediately below the 6 orifices where the exit plumes are assumed to have a circular cross-section. For this, beam placement was determined by adoption of the principles outlined in (Tsekenis et al., 2015) and (McCormick et al., 2013). The area of interest is shown in detail in fig 15. In order to define the edges of the plume exiting each orifice, each plume's circular cross-section is 'bound' by 4 beams. In order to quantify the concentration within the plume, the centre of each plume is crossed by 5 beams. 4 additional beams are located outside the area of interest $(d= \pm 12 \mathrm{~mm})$ to provide quantitative information about the background concentration. It is easy to envisage how the available beams can be concentrated one level further, in a single exit orifice, to further enhance imaging resolution.
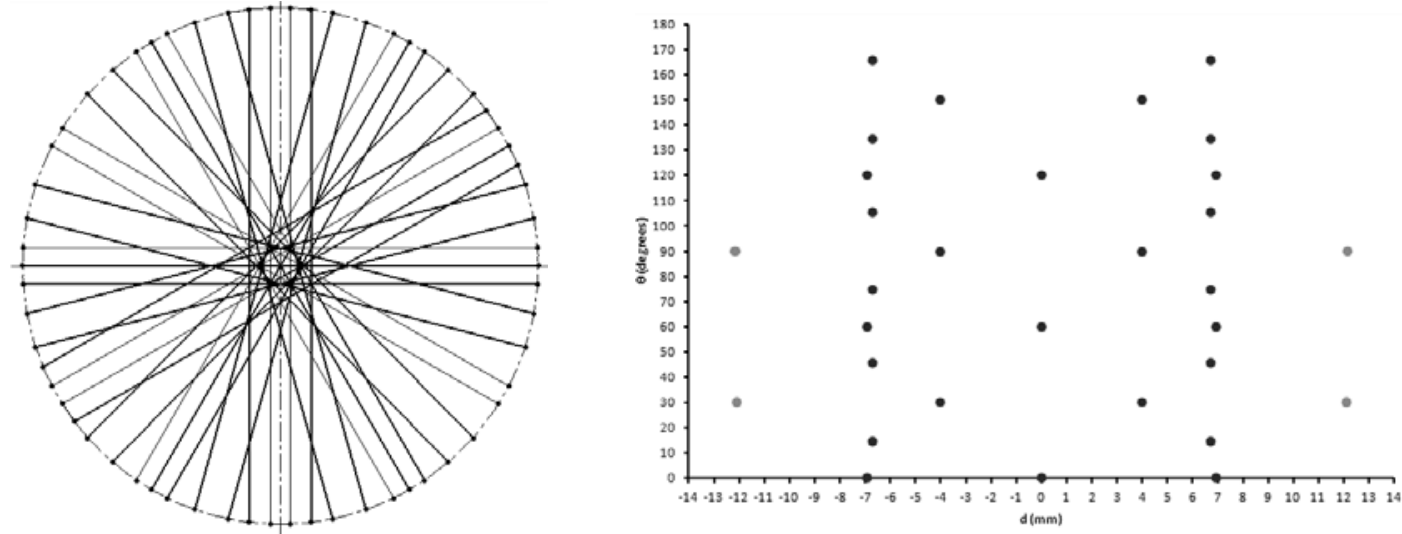
Fig 14: 31-beam tomography array (left) and sinogram representation (right) to image the main combustion chamber with pre-chamber emphasis.

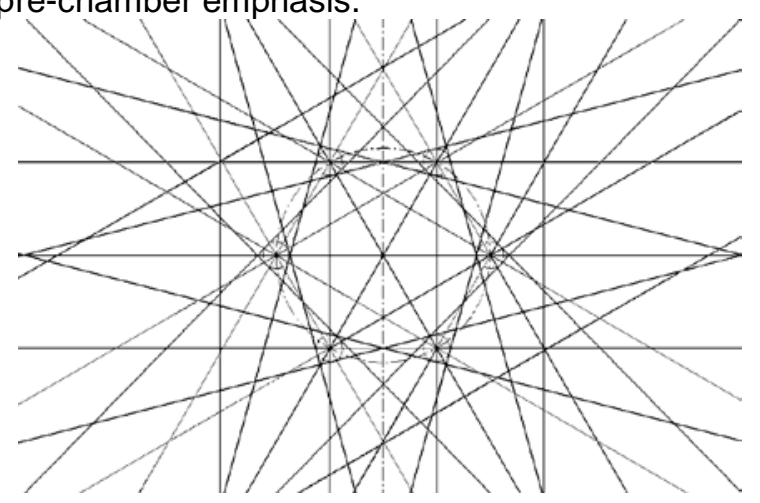

Fig 15: Detail of the 31-beam array of fig 14. Shown here also are the 6 circular areas of interest and corresponding beam locations.

\section{Conclusions}

In this paper we have presented the first steps towards the first application of Chemical Species Tomography to visualise the in-cylinder methane concentration distribution in a marine engine. A novel, minimally-intrusive optical access technique enables engine operation at the maximum rated cylinder pressure, offering insight beyond the limits of traditional optical diagnostic techniques. At these conditions, the spectroscopic behaviour of methane must be carefully studied. The spectroscopy results from modelling using the HITRAN database were encouraging; the line-strength weakening at high temperature partially restores the absorption features, making spectroscopic access viable despite the severe pressure-broadening. The spectroscopic behaviour of methane was also investigated experimentally and the results compared to the model. Subtle spectroscopic features were identified near the spectral regions of interest which could contribute to the methane concentration signal at elevated pressures. To access the features we propose a novel concept: a hybrid of Direct Absorption and Wavelength Modulation Spectroscopy with real-time switchover. This hybrid technique will provide the tomographic reconstruction input data from the 31-beams of the custom beam-array designed and optimised to visualise the gas plumes exiting the pre-chamber. Further work will initially focus on extending the current high-temperature methane spectroscopy experimental results to higher pressures. The additional insight into the subtle absorption features of methane will determine the optimum laser wavelength choice to achieve accurate concentration measurements across the engine operating regime. Subsequently, the 31-beam tomography beam array will be fabricated to demonstrate the system in-situ.

\section{Acknowledgements}

The authors acknowledge the financial and technical contributions received from the Engineering and Physical Sciences Research Council (EPSRC), Wärtsilä plc. and Lund University.

\section{References}

Aldén, M., Bood, J., Li, Z., Richter, M., 2011. Visualization and understanding of combustion processes using spatially and temporally resolved laser diagnostic techniques. Proc. Combust. Inst. 33, 69-97. doi:10.1016/j.proci.2010.09.004

Bakar, R.A., Semin, 2008. A Technical Review of Compressed Natural Gas as an Alternative Fuel for Internal Combustion Engines. Am. J. Eng. Appl. Sci. 1, 302-311. doi:10.3844/ajeassp.2008.302.311

Banwell, C., Mccash, E., 1994. Fundamentals for Molecular Spectroscopy, 4 edition. ed. McGraw-Hill Higher Education, London; New York.

Burns, D.A., Ciurczak, E.W. (Eds.), 2007. Handbook of Near-Infrared Analysis, Third Edition, 3 edition. ed. CRC Press, Boca Raton.

Carey, S.J., McCann, H., Hindle, F.P., Ozanyan, K.B., Winterbone, D.E., Clough, E., 2000. Chemical species tomography by near infra-red absorption. Chem. Eng. J. 77, 111-118. doi:10.1016/S13858947(99)00139-4

Cubillas, A.M., Silva-Lopez, M., Lazaro, J.M., Conde, O.M., Petrovich, M.N., Lopez-Higuera, J.M., 2007. Methane detection at 1670-nm band using a hollow-core photonic bandgap fiber and a multiline algorithm. Opt. Express 15, 17570. doi:10.1364/OE.15.017570 
Dantas, H.V., Barbosa, M.F., Nascimento, E.C.L., Moreira, P.N.T., Galvão, R.K.H., Araújo, M.C.U., 2014. Screening analysis of natural gas with respect to methane content by near-infrared spectrometry. Microchem. J. 114, 210-215. doi:10.1016/j.microc.2014.01.003

Frankenberg, C., Warneke, T., Butz, A., Aben, I., Hase, F., Spietz, P., Brown, L.R., 2008. Pressure broadening in the $2 \mathrm{v} 3$ band of methane and its implication on atmospheric retrievals. Atmos Chem Phys 8, 5061-5075. doi:10.5194/acp-8-5061-2008

Gao, Q., Zhang, Y., Yu, J., Wu, S., Zhang, Z., Zheng, F., Lou, X., Guo, W., 2013. Tunable multi-mode diode laser absorption spectroscopy for methane detection. Sens. Actuators Phys. 199, 106-110. doi:10.1016/j.sna.2013.05.012

Gao, X., Fan, H., Huang, T., Wang, X., Bao, J., Li, X., Huang, W., Zhang, W., 2006. Natural gas pipeline leak detector based on NIR diode laser absorption spectroscopy. Spectrochim. Acta. A. Mol. Biomol. Spectrosc. 65, 133-138. doi:10.1016/j.saa.2005.09.046

Kopecek, H., Charareh, S., Lackner, M., Forsich, C., Winter, F., Klausner, J., Herdin, G., Weinrotter, M., Wintner, E., 2005. Laser Ignition of Methane-Air Mixtures at High Pressures and Diagnostics. J. Eng. Gas Turbines Power 127, 213-219. doi:10.1115/1.1805550

Lackner, M., Totschnig, G., Winter, F., Ortsiefer, M., Amann, M.-C., Shau, R., Rosskopf, J., 2003. Demonstration of methane spectroscopy using a vertical-cavity surface-emitting laser at $1.68 \mu \mathrm{m}$ with up to $5 \mathrm{MHz}$ repetition rate. Meas. Sci. Technol. 14, 101. doi:10.1088/0957-0233/14/1/315

Lengden, M., Cunningham, R., Johnstone, W., 2013. Tunable Diode Laser Based Concentration Measurements of Water Vapour and Methane on a Solid Oxide Fuel Cell. J. Light. Technol. 31, 13541359. doi:10.1109/JLT.2013.2247378

Li, H., Rieker, G.B., Liu, X., Jeffries, J.B., Hanson, R.K., 2006. Extension of wavelength-modulation spectroscopy to large modulation depth for diode laser absorption measurements in high-pressure gases. Appl. Opt. 45, 1052. doi:10.1364/AO.45.001052

McCormick, D., Twynstra, M.., Daun, K.., McCann, H., 2013. Optimising laser absorption tomography beam arrays for imaging chemical species in gas turbine engine exhaust plumes, in: Proc. 7th World Congress on Industrial Process Tomography. International Society for Industrial Process Tomography, krakow, Poland, pp. 505-514.

McGettrick, A.J., Johnstone, W., Cunningham, R., Black, J.D., 2009. Tunable Diode Laser Spectroscopy With Wavelength Modulation: Calibration-Free Measurement of Gas Compositions at Elevated Temperatures and Varying Pressure. J. Light. Technol. 27, 3150-3161. doi:10.1109/JLT.2008.2008729

McLean, A.B., Mitchell, C.E.J., Swanston, D.M., 1994. Implementation of an efficient analytical approximation to the Voigt function for photoemission lineshape analysis. J. Electron Spectrosc. Relat. Phenom. 69, 125-132. doi:10.1016/0368-2048(94)02189-7

Platt, U., Stutz, J., 2008a. Differential Absorption Spectroscopy, in: Differential Optical Absorption Spectroscopy, Physics of Earth and Space Environments. Springer Berlin Heidelberg, pp. 135-174.

Platt, U., Stutz, J., 2008b. Interaction of Molecules with Radiation, in: Differential Optical Absorption Spectroscopy, Physics of Earth and Space Environments. Springer Berlin Heidelberg, pp. 77-90.

Rothman, L.S., Gordon, I.E., Babikov, Y., Barbe, A., Chris Benner, D., Bernath, P.F., Birk, M., Bizzocchi, L., Boudon, V., Brown, L.R., Campargue, A., Chance, K., Cohen, E.A., Coudert, L.H., Devi, V.M., Drouin, B.J., Fayt, A., Flaud, J.-M., Gamache, R.R., Harrison, J.J., Hartmann, J.-M., Hill, C., Hodges, J.T., Jacquemart, D., Jolly, A., Lamouroux, J., Le Roy, R.J., Li, G., Long, D.A., Lyulin, O.M., Mackie, C.J., Massie, S.T., Mikhailenko, S., Müller, H.S.P., Naumenko, O.V., Nikitin, A.V., Orphal, J., Perevalov, V., Perrin, A., Polovtseva, E.R., Richard, C., Smith, M.A.H., Starikova, E., Sung, K., Tashkun, S., Tennyson, J., Toon, G.C., Tyuterev, V.G., Wagner, G., 2013. The HITRAN2012 molecular spectroscopic database. J. Quant. Spectrosc. Radiat. Transf., HITRAN2012 special issue 130, 4-50. doi:10.1016/j.jqsrt.2013.07.002

Shah, A., Tunestal, P., Johansson, B., 2014. Effect of Relative Mixture Strength on Performance of Divided Chamber "Avalanche Activated Combustion" Ignition Technique in a Heavy Duty Natural Gas Engine (SAE Technical Paper No. 2014-01-1327). SAE International, Warrendale, PA. 
Shemshad, J., 2013. Design of a fibre optic sequential multipoint sensor for methane detection using a single tunable diode laser near $1666 \mathrm{~nm}$. Sens. Actuators B Chem. 186, 466-477.

doi:10.1016/j.snb.2013.06.003

Shemshad, J., Aminossadati, S.M., Bowen, W.P., Kizil, M.S., 2011. Effects of pressure and temperature fluctuations on near-infrared measurements of methane in underground coal mines. Appl. Phys. B 106, 979-986. doi:10.1007/s00340-011-4801-z

Sick, V., 2013. High speed imaging in fundamental and applied combustion research. Proc. Combust. Inst. 34, 3509-3530. doi:10.1016/j.proci.2012.08.012

Srinivasan, K.K., Krishnan, S.R., Singh, S., Bell, S.R., Gong, W., Fiveland, S.B., Willi, M., 2004. The Advanced Injection Low Pilot Ignited Natural Gas Engine: A Combustion Analysis. J. Eng. Gas Turbines Power 128, 213-218. doi:10.1115/1.1915428

Terzija, N., Davidson, J.L., Garcia-Stewart, C.A., Wright, P., Ozanyan, K.B., Pegrum, S., Litt, T.J., McCann, H., 2008. Image optimization for chemical species tomography with an irregular and sparse beam array. Meas. Sci. Technol. 19, 094007. doi:10.1088/0957-0233/19/9/094007

Terzija, N., Karagiannopoulos, S., Begg, S., Wright, P., Ozanyan, K., McCann, H., 2015. Tomographic imaging of the liquid and vapour fuel distributions in a single-cylinder direct-injection gasoline engine. Int. J. Engine Res. 16, 565-579. doi:10.1177/1468087414544178

Tsekenis, S.A., Tait, N., McCann, H., 2015. Spatially resolved and observer-free experimental quantification of spatial resolution in tomographic images. Rev. Sci. Instrum. 86, 035104. doi:10.1063/1.4913922

Well, B. van, Murray, S., Hodgkinson, J., Pride, R., Strzoda, R., Gibson, G., Padgett, M., 2005. An open-path, hand-held laser system for the detection of methane gas. J. Opt. Pure Appl. Opt. 7, S420. doi:10.1088/1464-4258/7/6/025

Wright, P., Terzija, N., Davidson, J.L., Garcia-Castillo, S., Garcia-Stewart, C., Pegrum, S., Colbourne, S., Turner, P., Crossley, S.D., Litt, T., Murray, S., Ozanyan, K.B., McCann, H., 2010. High-speed chemical species tomography in a multi-cylinder automotive engine. Chem. Eng. J., Application of Process Tomography 158, 2-10. doi:10.1016/j.cej.2008.10.026 